\section{Rhinitisdiagnostik bald noch einfacher?}

\section{Gute Nachrichten für Rhinitispatienten: Möglicherweise stehen bald auch für die klinische Routine Tryptase- und ECP-Tests als Marker aus dem Nasensekret zur Verfügung, mit denen die nasale Entzündungsreaktionen einfach und ohne großen Aufwand diagnostiziert werden können. Grundlage hierfür ist die unterschiedliche Mediatorfreisetzung bei den verschiedenen Formen der Rhinitis.}

Als Mediatoren der nasalen Entzündungsreaktion, einem wesentlichen pathologischen Merkmal der allergischen Rhinitis, spielen die Tryptase aus den Mastzellen und das Eosinophile kationische Protein (ECP) aus den eosinophilen Granulozyten eine Rolle.

Tryptase, eine tetramere SerinproWirkungen, kommt sowohl im Serum als auch im Nasensekret vor und gilt als Nachweis einer Mastzellaktivierung. Für die klinische Diagnostik eignet sie sich besser als Histamin, da sie länger stabil bleibt. Der ECP-Spiegel reflektiert den Aktivierungszustand der eosinophilen Granulozyten, die an der Lyse der Atemwegsschleimhäute beteiligt sind.

\section{Tryptasekonzentrationen weisen den diagnostischen Weg}

$\mathrm{Ob}$ sich die beiden Entzündungsmediatoren Tryptase und ECP, die leicht aus dem Nasensekret zu gewinnen sind, als Marker für die Diagnostik verschiedener Rhinitiden eignen, wurde in einer Querschnittsstudie mit 120 Patienten untersucht. Die rhinologischen Krankheitsbilder ermittelte man mittels Pricktests, spezifischen IgE-Bestimmungen und Provokationstests. Die Nasensekretentnahme erfolgte mit Hilfe von Wattestreifen, die für 5 Minuten in den mittleren Nasengang eingelegt wurden. Zur Bestimmung von Tryptase und ECP dienten zuerst präklinische RIA-Systeme, später CAP-FEIA- und UNI-CAP-Systeme. tease mit verschiedenen klinischen
Die Untersuchungsergebnisse belegen die differentielle Sekretion der Tryptase und des eosinophilen kationischen Proteins (ECP) bei verschiedenen Formen der Rhinitis. Tryptase tritt dabei häufiger bei Allergien als bei anderen Entzündungen auf, wie aus der Grafik ersichtlich ist. Die eosinophile Entzündung, gemessen am ECP, zeigt sich dagegen weniger spezifisch für allergische Erkrankungen.

Der zeitliche Ablauf der nasalen Entzündung ließ sich in nasalen Provokationstests mit 7 Gräserallergikern und 3 Kontrollpersonen direkt nachweisen, indem man den Patienten nach der Allergenprovokation stündlich Nasensekret entnahm. Dabei zeigte sich, daß die Tryptase als Mediator der Frühphase bereits nach 15 Minuten auftritt, ECP steigt dagegen erst in der Spätphase der allergischen Sofortreaktion (nach 4 Stunden). Weiterführende Untersuchungen ergaben, daß eine medikamentöse Intervention bzw. Immuntherapien zur Abnahme der beiden Mediatoren im Nasensekret führen.

\section{Normwerte für den klinischen Einsatz fehlen noch}

Nichtinvasive immunologische Messungen direkt an der Nase scheinen also zumindest für die Zukunft auch in der klinischen Routine anwendbar zu sein: Die Studie läßt auf die Möglichkeit einer lokalen Querschnittsdiagnostik an der Nase mittels Sekretbestimmung hoffen. Um die beiden Mediatoren ECP und Tryptase jedoch breit in der Diagnostik einsetzen zu können, müssen nun in einem größeren Kollektiv Normwerte festgelegt werden.

(jn)

Quelle: Vortrag von G. Rasp (München): „Klinische Anwendung von Entzündungsmediatoren im Nasensekret: Tryptase und ECP, anlâslich des 25. Kongresses des Arzteverbande Deutscher Allergologen, Göttingen 1998

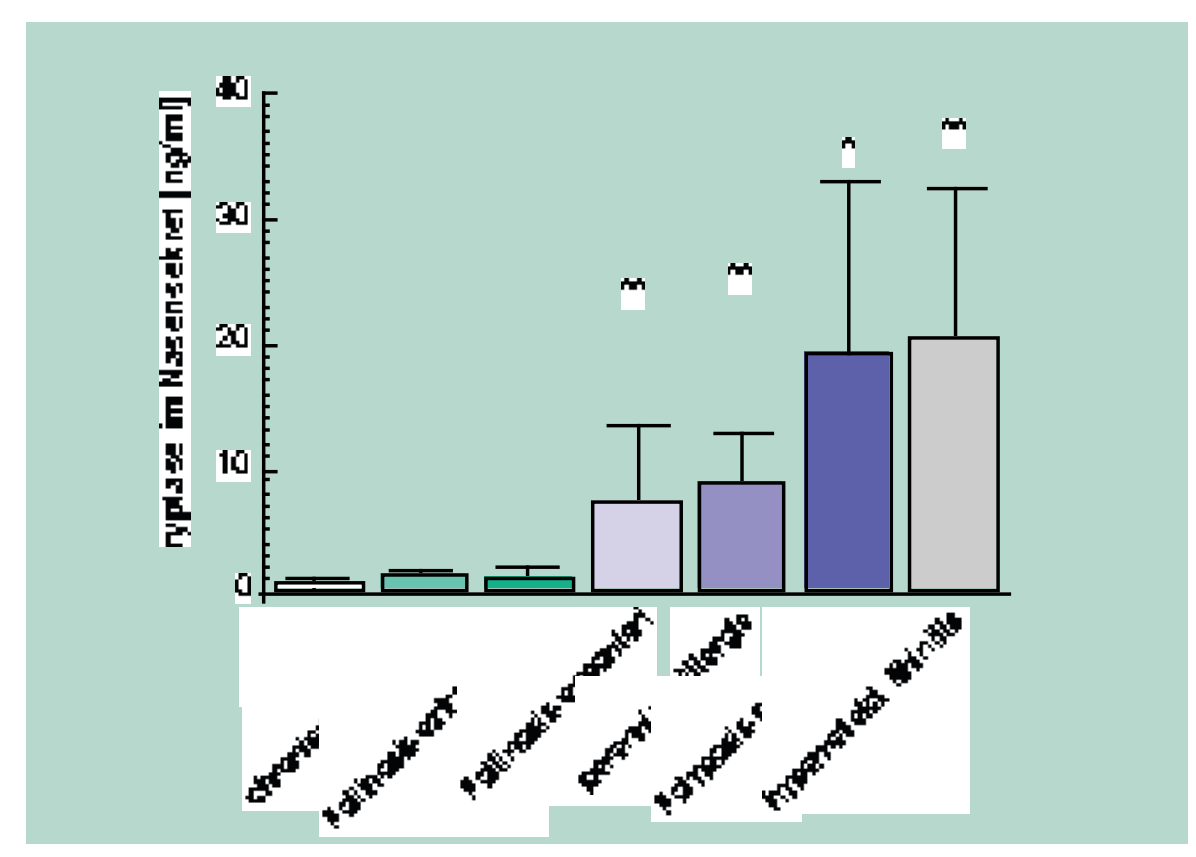

Unterschiedliche Tryptasekonzentrationen im Nasensekret bei 107 Patienten bei verschiedenen entzündlichen Veränderungen im nasalen Bereich $\left({ }^{*} p<0,05 ;{ }^{* *} p<0,01\right)$. 